\title{
Prevalence of Obstructive Lung Disease in Asymptomatic Gas Field Workers
}

\author{
Fatima Zaina ${ }^{1}$, Salva Arshad ${ }^{2}$, Jawed Abubaker ${ }^{3}$, Arsalan Ahmed ${ }^{3}$, Musa Karim ${ }^{4}$ \\ 1. Pulmonology, Dr. Ziauddin University and Hospital, Karachi, PAK 2. Pulmonology, National Institute of \\ Cardiovascular Diseases (NICVD), Karachi, PAK 3. Internal Medicine, Dr. Ziauddin University and Hospital, Karachi,
} PAK 4. Miscellaneous, National Institute of Cardiovascular Diseases (NICVD), Karachi, PAK

Corresponding author: Musa Karim, mkarim.nicvd@gmail.com

\section{Abstract}

\section{Introduction}

Obstructive lung disease, if not managed appropriately and in a timely manner, increases morbidity and mortality. The aim of this study was to see an obstruction on spirometry reports of clinically asymptomatic oil and gas field workers.

\section{Methods}

In this retrospective observational study, spirometry reports performed at the pulmonary function laboratory of Ziauddin Hospital and University, Karachi, were reviewed. All reports were of the clinically asymptomatic employees of an oil and gas company in Pakistan, who presented for their routine assessment. Obstructive impairment was defined as a forced expiratory volume in one second (FEV1) to forced vital capacity (FVC) ratio of less than 0.7 .

\section{Results}

Of the total of 199 spirometry reports, 197 (99\%) were of male employees. The mean age of the employees was $30.52 \pm 8.24$ years and 46 (23.1\%) employee were smokers. Obstruction was observed in 48 (24.1\%) of the reports of the employees with 13 (27.1\%) smokers and 35 (72.9\%) non-smokers. No statistically significant association between obstruction and gender, age, and smoking was observed.

\section{Conclusion}

In this study, we observed obstructive impairment in around one-fourth of the otherwise clinically asymptomatic oil and gas field workers with no apparent impact of baseline smoking behavior.

Received 10/26/2018 Review began 11/02/2018 Review ended 11/09/2018 Published 11/12/2018

๑) Copyright 2018 Zaina et al. This is an open access article distributed under the terms of the Creative Commons Attribution License CC-BY 3.0., which permits unrestricted use, distribution, and reproduction in any medium, provided the original author and source are credited.
Categories: Pulmonology, Environmental Health, Epidemiology/Public Health

Keywords: spirometry, obstructive lung disease, oil and gas

\section{Introduction}

Chronic obstructive pulmonary disease (COPD), largely irreversible, is a progressive airflow obstruction predominantly attributed to smoking in the middle to late age population segment [1]. Smoking is considered to be the only risk factor of COPD, however, mounting evidence suggestive of other etiologically important factors, which, either alone or in combination with smoking, relate to the COPD [1-2]. Among other etiological and environmental factors that are attributable to COPD, occupational exposure is reported to be responsible for at least $15 \%$ to $20 \%$ of all cases of COPD [3-5].

Occupational exposure to gas, fumes, and organic and inorganic dust is an underestimated group of obstructive lung diseases (asthma and chronic obstructive pulmonary disease) [6-7]. Multiple, randomized controlled trials showed that exposure to workplace dust and fumes is associated with increased airflow limitation, emphysema, and gas trapping, as demonstrated by a computed tomography (CT) scan, in both men and women [8]. National Health and Nutrition Examination Survey III, a large U.S. population-based survey of almost 10,000 adults aged 30-75 years, anticipated that the portion of COPD attributable to workplace exposures was $19.2 \%$ in general and $31.1 \%$ among never-smokers [9].

Obstructive lung diseases are underestimated because they usually present clinically when they are slightly advanced. An early diagnosis of the disease is crucial in treating, preventing, and decreasing the disease burden, which is increasing in a threatening manner. Globally, aggressive measures are being taken to prevent the disease so that the disease burden itself goes down. In this regard, many diagnostic tools have been used for the detection of the disease, among which the pulmonary function test (PFT) has a pivotal role [10]. Early detection of obstructive impairment can be done confidently with PFTs [11-12]. The aim of this study was to see any abnormality in a selected population that works in oil- and gas-exposed areas and are 


\section{Cureus}

clinically asymptomatic.

\section{Materials And Methods}

After taken the permission of the ethical review committee of the institution for this retrospective observational study, a total of 199 spirometry reports were reviewed, which were performed at the pulmonary function laboratory at Ziauddin Hospital and University, Karachi, during the period August 2015 to July 2016. All reports were of the clinically asymptomatic employees of an oil and gas company in Pakistan, who presented for their routine assessment. Spirometry reports of employees with a prior history of lung disease were excluded. Spirometry was performed by trained and certified staff using the portable Vitalograph (Kansas, USA) compact expert model number: 6600. Maneuvers were performed thrice for forced vital capacity (FVC), forced expiratory volume in one second (FEV1), and ratio FEV1/FVC for the diagnosis of obstruction. Obstructive impairment was defined as an FEV1 to FVC ratio of less than 0.7. The participants whose results came out to be abnormal were given a short-acting beta agonist (Salbutamol $200 \mathrm{mcg}$ ) and repeat spirometry was done for the post-bronchodilator change. A predefined structural questionnaire was used for the retrieval of required information, including age, gender, smoking status, family history of asthma, and obstruction as per spirometry. IBM SPSS Statistics for Windows, Version 21.0. (IBM Corp., Armonk, NY, US) was used to enter and analyze the collected data. Mean \pm standard deviation (SD) for continuous variables, like age in years, frequency, and percentages, were calculated for categorical variables. The Chi-square test was applied to evaluate the association between categorical variables. A two-sided pvalue $\leqslant 0.05$ was taken as the criteria for statistical significance.

\section{Results}

Of the total of 199 spirometry reports, 197 (99\%) were of male employees and only 2 (1\%) were of female employees. The mean age of the employees was $30.52 \pm 8.24$ years, with 116 (58.3\%) employees between 18 and 30 years of age. None of the employees had a family history of asthma and 46 (23.1\%) employees were smokers. The baseline characteristics of the employees are summarized in Table 1.

\begin{tabular}{|l|l|l|}
\hline Characteristics & Frequency & Percentage \\
\hline Male & 197 & $99.0 \%$ \\
\hline Female & 2 & $1.0 \%$ \\
\hline Age (mean \pm SD) & $30.52 \pm 8.24$ years & \\
\hline 8 to 30 years & 116 & $58.3 \%$ \\
More than 30 years & 83 & $41.7 \%$ \\
\hline Smoker & 46 & $23.1 \%$ \\
\hline Family History - Asthma & 0 & $0.0 \%$ \\
\hline
\end{tabular}

TABLE 1: Baseline characteristics

Of all the asymptomatic employees, 48 (24.1\%) were found to have an obstruction, out of which 13 (27.1\%) were smokers and 35 (72.9\%) were non-smokers. No statistically significant association between obstruction and gender, age, and smoking was observed with chi-square p-values of 0.432, 0.094, and 0.454, respectively. The presence of an obstruction by the baseline characteristics of the employees is presented in Table 2 . 


\section{Cureus}

\begin{tabular}{|c|c|c|c|}
\hline \multirow{2}{*}{ Characteristics Frequency (row \%) } & \multicolumn{2}{|l|}{ Obstruction } & \multirow{2}{*}{${ }^{\star \star}$ p-value } \\
\hline & Yes & No & \\
\hline Overall & $48(24.1 \%)$ & $151(75.9 \%)$ & - \\
\hline \multicolumn{4}{|l|}{ Gender } \\
\hline Male & $48(24.4 \%)$ & $149(75.6 \%)$ & \multirow{2}{*}{0.423} \\
\hline Female & $0(0.0 \%)$ & $2(100.0 \%)$ & \\
\hline \multicolumn{4}{|l|}{ Age } \\
\hline 18 to 30 years & $23(19.8 \%)$ & $93(80.2 \%)$ & \multirow{2}{*}{0.094} \\
\hline More than 30 years & $25(30.1 \%)$ & $58(69.9 \%)$ & \\
\hline \multicolumn{4}{|l|}{ Smoking } \\
\hline Smokers & $13(28.3 \%)$ & $33(71.7 \%)$ & \multirow{2}{*}{0.454} \\
\hline Non-smokers & $35(22.9 \%)$ & $118(77.1 \%)$ & \\
\hline
\end{tabular}

\section{TABLE 2: Obstruction by employees baseline characteristics}

${ }^{\star *} \mathrm{p}$-values are based on the chi-square test

\section{Discussion}

The aim of this study was to evaluate abnormal spirometry in individuals who were otherwise healthy and presented for screening as a part of their required assessment. As the data we selected was of a population that worked in the oil and gas fields, we anticipated that these recruits will have some level of airway obstruction/reactive airway disease. In order to do this, we observed 199 spirometry reports done as an outpatient in our pulmonary function laboratory.

Our data demonstrated that 48 (24.1\%) employees demonstrated an obstruction/reactive airway disease as detected by spirometry, with no apparent impact of baseline characteristics, such as gender, age, and smoking status. Several studies across the globe have established that occupational exposure to vapors, gases, dust, or fumes (VGDF), to a certain extent, is the cause of COPD development [1,5,13-17]. The extent of COPD due to occupational exposure varies from $15 \%$ to $20 \%[3-5,17]$. These variations are partly due to varying occupational categories and the diagnostic criteria of COPD. The results of our study for oil and gas field workers are slightly higher than those reported in past studies. There are uncertainties in the literature about certain occupational exposures: whether it increases the risk of COPD independently or in combination with smoking [1]. Owing to the fact that smoking is the only and most important risk factor of COPD, it is important to address the potential modification effect of smoking while studying any underlying occupational relationship with COPD. In our study, obstructions among smokers and nonsmokers were observed to be $28.3 \%$ vs. $22.9 \%$, respectively, with a chi-square p-value of 0.454 (statistically insignificant). This insignificant association of smoking with obstruction, assessed by spirometry, does reveal the potential evidence that occupational exposure among the oil and gas workers could enhance the risk of COPD regardless of baseline smoking behavior. Similarly, no significant association of obstruction was observed with age but the percentage of obstruction was relatively higher among employees more than 30 years of age, $30.1 \%$ vs. $19.8 \%$ with the p-value of 0.094 , as compared to employees of age between 18 and 30 years. This relatively higher rate can be attributed to the fact that employees of relatively older ages are supposed to have more years of exposure to gas, fumes and organic and inorganic dust.

After reviewing the data, screening at the time of recruiting individuals for a job that requires a risk of exposure to a noxious material is a dire need. We need protocols to periodically screen the oil and gas field workers for any reactive airway disease due to exposure to the hazardous material. This information is important in either providing protection or preventing the disease in workers in the exposed environment. As there are no protocols for the screening of persons who are working or about to work in an exposed area, this study will help in developing some guidelines for recruitment. In future also, this subject can be further evaluated by following the patients prospectively to look for the effects of the noxious stimuli they have been exposed to.

The retrospective design, small sample size, and single oil and gas company coverage may limit the generalizability of the research findings. 


\section{Conclusions}

In this study, we observed an obstructive impairment in around one-fourth of the otherwise clinically asymptomatic oil and gas field workers, with no apparent impact of baseline smoking behavior. We suggest screening protocols should be made for the recruitment of new employees and a periodic assessment of existing oil and gas field workers be put in place so that better protective and preventive strategies can be formed. Such initiatives will help us decrease the overall burden of disease in our society.

\section{Additional Information \\ Disclosures}

Human subjects: Consent was obtained by all participants in this study. Ethical Review Committee, Dr. Ziauddin University and Hospital, Karachi, Pakistan issued approval DZH-0805-001. The study was approved by the Ethical Review Committee of Dr. Ziauddin University and Hospital, Karachi, Pakistan, for a study duration of August 2015 to July 2016. Animal subjects: All authors have confirmed that this study did not involve animal subjects or tissue. Conflicts of interest: In compliance with the ICMJE uniform disclosure form, all authors declare the following: Payment/services info: All authors have declared that no financial support was received from any organization for the submitted work. Financial relationships: All authors have declared that they have no financial relationships at present or within the previous three years with any organizations that might have an interest in the submitted work. Other relationships: All authors have declared that there are no other relationships or activities that could appear to have influenced the submitted work.

\section{References}

1. Cullinan P: Occupation and chronic obstructive pulmonary disease (COPD). Br Med Bull. 2012, 104:143-161. 10.1093/bmb/lds028

2. Hurd SS, Lenfant C: COPD good lung health is the key . Lancet. 2005, 366:1832-1834. 10.1016/S01406736(05)67634-9

3. Blanc PD, Toren K: Occupation in chronic obstructive pulmonary disease and chronic bronchitis: an update . Int J Tuberc Lung Dis. 2007, 11:251-257.

4. Boschetto P, Quintavalle S, Miotto D, Cascio NL, Zeni E, Mapp CE: Chronic obstructive pulmonary disease (COPD) and occupational exposures. J Occup Med Toxicol. 2006, 1:11. 10.1186/1745-6673-1-11

5. Blanc PD: Occupation and COPD: a brief review. J Asthma. 2012, 49:2-4. 10.3109/02770903.2011.611957

6. Eisner MD, Anthonisen N, Coultas D, et al.: An official American Thoracic Society public policy statement: novel risk factors and the global burden of chronic obstructive pulmonary disease. Am J Respir Crit Care Med. 2010, 182:693-718. 10.1164/rccm.200811-1757ST

7. Paulin LM, Diette GB, Blanc PD, et al.: Occupational exposures are associated with worse morbidity in patients with chronic obstructive pulmonary disease. Am J Respir Crit Care Med. 2015, 191:557-565. 10.1164/rccm.201408-1407OC

8. Marchetti N, Garshick E, Kinney GL, et al.: Association between occupational exposure and lung function, respiratory symptoms, and high-resolution computed tomography imaging in COPDGene. Am J Respir Crit Care Med. 2014, 190:756-762. 10.1164/rccm.201403-04930C

9. Hnizdo E, Sullivan PA, Bang KM, Wagner G: Association between chronic obstructive pulmonary disease and employment by industry and occupation in the US population: a study of data from the Third National Health and Nutrition Examination Survey. Am J Epidemiol. 2002, 156:738-746. 10.1093/aje/kwf105

10. Townsend MC, Lockey JE, Velez H, et al.: Spirometry in the occupational setting. Int J Occup Environ Med. 2000, 72:228-245

11. Soriano JB, Zielinski J, Price D: Screening for and early detection of chronic obstructive pulmonary disease . Lancet. 2009, 374:721-732. 10.1016/S0140-6736(09)61290-3

12. du Bois RM: Evolving concepts in the early and accurate diagnosis of idiopathic pulmonary fibrosis . Clin Chest Med. 2006, 27:17-25. 10.1016/i.ccm.2005.08.001

13. Govender N, Lalloo UG, Naidoo RN: Occupational exposures and chronic obstructive pulmonary disease: a hospital based case-control study. Thorax. 2011, 66:597-601. 10.1136/thx.2010.149468

14. Rodríguez E, Ferrer J, Martí S, Zock JP, Plana E, Morell F: Impact of occupational exposure on severity of COPD. Chest. 2008, 134:1237-1243. 10.1378/chest.08-0622

15. Salvi SS, Barnes PJ: Chronic obstructive pulmonary disease in non-smokers . Lancet. 2009, 374:733-743. 10.1016/S0140-6736(09)61303-9

16. Behrendt CE: Mild and moderate-to-severe COPD in nonsmokers: distinct demographic profiles . Chest. 2005, 128:1239-1244. 10.1378/chest.128.3.1239

17. Fishwick D, Barber CM, Darby AC: Review series: occupational and environmental lung disease: chronic obstructive pulmonary disease and the workplace. Chron Respir Dis. 2010, 7:113-122. 10.1177/1479972309354690 